\title{
Article \\ On the Design of a Decision Support System for Robotic Equipment Adoption in Construction Processes
}

\author{
Carmen Marcher ${ }^{1,2, *(\mathbb{D})}$, Andrea Giusti ${ }^{2}(\mathbb{D})$ and Dominik T. Matt ${ }^{1,2}$ (D) \\ 1 Faculty of Science and Technology, University of Bolzano, Piazza Università 5, 39100 Bolzano, Italy; \\ dominik.matt@unibz.it \\ 2 Fraunhofer Italia Research, via A.-Volta 13A, 39100 Bolzano, Italy; andrea.giusti@fraunhofer.it \\ * Correspondence: carmen.marcher@natec.unibz.it
}

Citation: Marcher, C.; Giusti, A.;

Matt, D.T. On the Design of a

Decision Support System for Robotic Equipment Adoption in Construction Processes. Appl. Sci. 2021, 11, 11415. https://doi.org/10.3390/app112311415

\section{Academic Editors: João M.}

F. Rodrigues, Pedro J. S. Cardoso and Marta Chinnici

Received: 29 October 2021

Accepted: 29 November 2021

Published: 2 December 2021

Publisher's Note: MDPI stays neutral with regard to jurisdictional claims in published maps and institutional affiliations.

Copyright: (C) 2021 by the authors. Licensee MDPI, Basel, Switzerland. This article is an open access article distributed under the terms and conditions of the Creative Commons Attribution (CC BY) license (https:// creativecommons.org/licenses/by/ $4.0 /)$.

\begin{abstract}
The construction sector is one of the major global economies and is characterised by low productivity and high inefficiencies, but could highly benefit from the introduction of robotic equipment in terms of productivity, safety, and quality. As the development and the availability of robotic solutions for the construction sector increases, the evaluation of their potential benefits compared to conventional processes that are currently adopted on construction sites becomes compelling. To this end, we exploit Bayesian decision theory and apply an axiomatic design guideline for the development of a decision-theoretic expert system that: (i) evaluates the utility of available alternatives based on evidence; (ii) accounts for uncertainty; and (iii) exploits both expert knowledge and preferences of the users. The development process is illustrated by means of exemplary use case scenarios that compare manual and robotic processes. A use case scenario that compares manual and robotic marking and spraying is chosen for describing the development process in detail. Findings show how decision making in equipment selection can be supported by means of dedicated systems for decision support, developed in collaboration with domain experts.
\end{abstract}

Keywords: equipment selection; construction robot; decision support system; axiomatic design; decision-theoretic expert system; construction industry; industry 4.0

\section{Introduction}

The broad adoption of automation and robotics is changing operations in many business sectors [1]. Even though the construction sector is one of the major economies, it suffers from inefficiencies and a low increase in productivity [2,3] and could, therefore, highly benefit from the introduction of automation and robotics. The adoption of robotic systems has the potential to increase safety, quality, productivity, and to reduce cost in construction processes [4-6]. During the last decades, the interest towards the development of robotic solutions for applications in the construction sector is constantly growing and their potential deployment is addressed in several works [5-8]. However, compared to other sectors, the construction industry can be considered as a traditional industry that is characterised by a lack of interest in innovation $[9,10]$ and a clear opposition to changes [11]. Even though the awareness of potential benefits of automation and robotics in the construction industry is increasing, the adoption of such technologies can be judged as slow [5].

The purpose of this study is to facilitate the comparison of advanced technological solutions with conventional manual construction processes. For this purpose, we illustrate how a system for decision support in the field of robotic equipment adoption can be designed and developed. This can be achieved by performing a structured evaluation of the impact that advanced technologies may have on safety, quality, productivity, and cost, and by assessing the utility of their adoption compared to conventional manual processes in an unbiased way. 
Current research shows that one way to support decision making in this field is the assessment of the actual performance of robots compared to traditional work practices on the construction site [12] and to provide adequate tools for supporting decision makers in the choice of replacing traditional processes with automated systems [13]. However, uncertainty and interdependencies, typical of construction operations, often hinder the definition of standardised approaches for decision-making [14]. Furthermore, when facing the decision of whether to replace conventional work methods with automated counterparts, the evaluation of alternatives should be able to reflect both preferences and knowledge of the users [15]. Equipment selection problems in construction can also be supported by different approaches and methods [16], as follows. The selection of cranes can be supported by multi-criteria decision-making methods that are able to evaluate project specific requirements, the characteristics of the equipment and economic factors [17,18]. Multicriteria decision-making methods that consider both qualitative and quantitative criteria are also employed for the selection of excavation machinery $[19,20]$. Construction machinery selection for infrastructure projects can be performed by using a decision support framework that evaluates risks and costs of the available alternatives [21]. In addition, the use of Building Information Modelling (BIM) is playing an important role in the field of automation and robotics in construction [22]. BIM is a methodology supporting the management of information within the construction sector. The result of the BIM methodology is a BIM model, a model that contains both geometric and semantic data of a building that can be employed along its whole lifecycle [23]. Current research shows how such BIM models can be integrated into robotic control systems to support the deployment of robotics in building construction and operation [24,25].

Nowadays, only few construction robots are actually used on real construction sites and comparisons to traditional or conventional processes are rarely available [26]. The performance of automated systems and traditional work methods for a given project can be assessed by showing how they perform on the level of single construction specific criteria or variables $[12,15,27]$. Analyses conducted in previous studies have shown that the key parameters considered when evaluating the utility of robotic systems compared to conventional processes are safety, quality, productivity, and cost [26]. Results of comparisons prove that construction robots have the capability to increase safety $[12,26,28]$, productivity $[12,26,28,29]$, and quality $[12,26,29]$ on construction sites. Some studies prove that robots may have a positive impact on cost [5,8], while others find that extra costs can occur for their deployment on site $[12,26]$. These considerations show that the deployment of robotic equipment on construction sites can have both benefits and drawbacks. Although many potential benefits of construction robots are described in the above-mentioned works, other barriers can prevent their widespread adoption in practice, such as a low propensity towards changing existing work practices $[5,11]$. This conservative attitude can be changed by involving domain experts in the definition of potential application areas and the expected impacts of construction robots. Previous studies show how experts can be engaged in the strategic definition of high-priority applications and the evaluation of the potential impacts of construction robots in these fields [5].

The aim of this research is to illustrate the design of a decision support system (DSS) for robotic equipment adoption that compares conventional and robotic processes by evaluating their utility. To achieve this aim we apply an axiomatic-design guideline [27] that supports the design of decision-theoretic expert systems based on Bayesian decision theory to aid equipment selection in construction. Axiomatic design is a system design methodology that is successfully applied in engineering, business, software, and product development [30]. Decision-theoretic expert systems allow one to assess the utility of the available options based on evidence, preference statements and expert knowledge. The approach is illustrated by means of exemplary use case scenarios of a research project that aims at developing configurable collaborative modular robotic platforms targeting use cases in construction. The use case scenarios are defined in collaboration with domain experts of the construction group participating in the project. We choose a use case scenario 
that considers the employment of collaborative robots for semiautonomous or teleoperated marking and spraying for the detailed description of the approach.

As a result, this research shows how a DSS in the field of robotic equipment adoption in construction can be designed. In particular, Axiomatic design allows us to divide the complex design process of the decision theoretic expert system into small and manageable steps that can be easily replicated in additional use cases. The structured involvement of domain experts in every development step increases the reliability of the DSS, fills lack of data with expert knowledge, and can increase the acceptance of the system by the potential users.

The remainder of this article is organised as follows: in Section 2 we introduce the preliminaries on the materials and methods considered; in Section 3 we describe the development of the prototype and the obtained results; in Section 4 we discuss the results; and in Section 5 we draw the conclusions.

\section{Preliminaries on Decision Theoretic Expert Systems}

Systems that exhibit artificial intelligence performing intellectual demanding tasks restricted to a specific problem domain are defined as expert systems [31]. Expert systems that rely on probabilistic networks are called decision-theoretic expert systems. These systems perform reasoning under uncertainty while maximizing expected utilities of the outcomes, and give advice on the best rational decision considering evidence and preference statements [32].

Decision networks, often referred to as influence diagrams or Bayesian decision networks, provide a formalism for modelling and solving decision problems following the principle of Maximum Expected Utility (MEU). Decision networks can be described as an extension of Bayesian networks [32,33]. A Bayesian network consists of a qualitative and a quantitative part, a Directed Acyclic Graph (DAG) with an associated joint probability distribution. The construction of Bayesian networks involves two main steps [31]: (i) the identification of variables and causal relations between them for establishing the DAG, and (ii) the elicitation of the conditional probability distributions of the random variables. By extending Bayesian networks with actions and utilities we obtain decision networks. Decision networks consist of the following components [31-33]: (i) decision nodes represent the problem variables and refer to the decisions or choices that are available for the decision maker; (ii) chance nodes represent the random variables, also referred to as information variables that may be observed to provide information for solving the problem; (iii) utility nodes represent the utility function of an agent and assess the expected utility for available choices or actions; and (iv) arcs denote the influences and relations between variables.

\section{Development of the Prototype}

We follow the axiomatic design-based guideline that is presented in Table 1. The guideline is based on [27] and the development steps are defined as follows: (i) identification of the problem domain; (ii) implementation of the knowledge base including the definition of the qualitative and quantitative part of the decision model; (iii) implementation of the inference engine with computation of the decision that yields the MEU, and Value of Information (VOI) analysis; and (iv) definition of the functionalities that allow the user to interact with the system. In addition to the guideline provided, we evaluate if the system provides reasonable output.

\subsection{Problem Domain}

The problem domain concerns the execution of construction tasks that can be performed both with the collaborative robot to be developed within the research project or with a conventional manual construction method. We consider the following use cases (UCs):

- UC1: Collaborative semi-autonomous transport and delivery of material and tools.

- UC2: Supervised and collaborative drilling. 
- UC3: Supervised and collaborative cutting.

- UC4: Semi-autonomous/teleoperated marking and spraying.

- UC5: Supervised/semi-autonomous documenting.

Within the project we will measure and verify the projected benefits and impact of developed technologies in the individual UCs through measurable Key Performance Indicators (KPIs) mutually agreed between the project partners. The results of the analysis of the UCs and related KPIs serve as a basis for defining the knowledge base of the DSS.

Table 1. Design guideline based on [27].

\begin{tabular}{|c|c|c|}
\hline \multicolumn{3}{|c|}{$\begin{array}{l}\text { 3.1 Problem domain } \\
\text { Use of the collaborative robot or use of the conventional construction process? }\end{array}$} \\
\hline 3.2 Knowledgebase & 3.3 Inference Engine & \multirow{5}{*}{$\begin{array}{l}\text { Computation of results based on } \\
\text { evidence and preferences. }\end{array}$} \\
\hline 3.2.1 Qualitative part & 3.3.1 MEU computation & \\
\hline $\begin{array}{l}\text { Definition of the variables to be } \\
\text { considered in the evaluation and } \\
\text { definition of the relations between them. }\end{array}$ & $\begin{array}{l}\text { Computation and selection of the } \\
\text { decision that yields the MEU. }\end{array}$ & \\
\hline 3.2.2 Quantitative part & 3.3.2 VOI analysis & \\
\hline $\begin{array}{l}\text { Definition of the numbers that are } \\
\text { necessary for performing the } \\
\text { computations. }\end{array}$ & $\begin{array}{l}\text { Computation of which information } \\
\text { should be acquired by the user. }\end{array}$ & \\
\hline Eval & $\begin{array}{l}\text { 3.5 Evaluation } \\
\text { of reasonableness of the output of }\end{array}$ & \\
\hline
\end{tabular}

\subsection{Knowledgebase}

Within the knowledgebase, the qualitative and the quantitative parts of the decision network are defined. We elicit the knowledge related to the problem domain by collecting expert knowledge and by analysing available literature that addresses the comparison of construction robots and conventional construction processes.

The relevant literature in this field is mapped by performing a manual search of articles and conference papers on Elsevier's database Scopus, a peer-review database in the field of engineering sciences. The search is limited to English articles and conference publications in the publication period from 2011 to April 2021. The search keyword is "construction robot ${ }^{* \prime}$. The screening of the abstracts and papers is performed to exclude articles with no to low relevance to our field of study. This reduces the data to 17 highly relevant items that are further analysed to extract the parameters that are relevant for our field of study. Out of these 17 remaining articles, only 11 do consider the comparison between conventional approaches and the use of robots for the execution of construction tasks and only nine contain relevant information in the field of robotic equipment adoption in construction processes.

This analysis allows one to define, in collaboration with domain experts, the variables to be considered for comparing robotic processes with conventional processes within our research. In Table 2 we provide the description of the variables to be considered in the assessment of the available options. The variables are presented along with the KPIs of the project, their relevance for the different domains, their consideration within the previously introduced UCs, and the supporting literature.

\subsubsection{Qualitative Part}

The elicitation of the qualitative part of the decision model is based on the list of variables presented in Table 2. Initially, we define the overall qualitative model, that considers all the UCs in which the robotic system shall be applied (Figure 1). The decision node (illustrated as a rectangle) represents the available choices, the chance nodes (illustrated as ovals) represent the random variables involved in the decision along with their relevance 
for the different UCs, the utility node (illustrated as a diamond) represents the utility function, and arcs represent the causal relations between the variables.

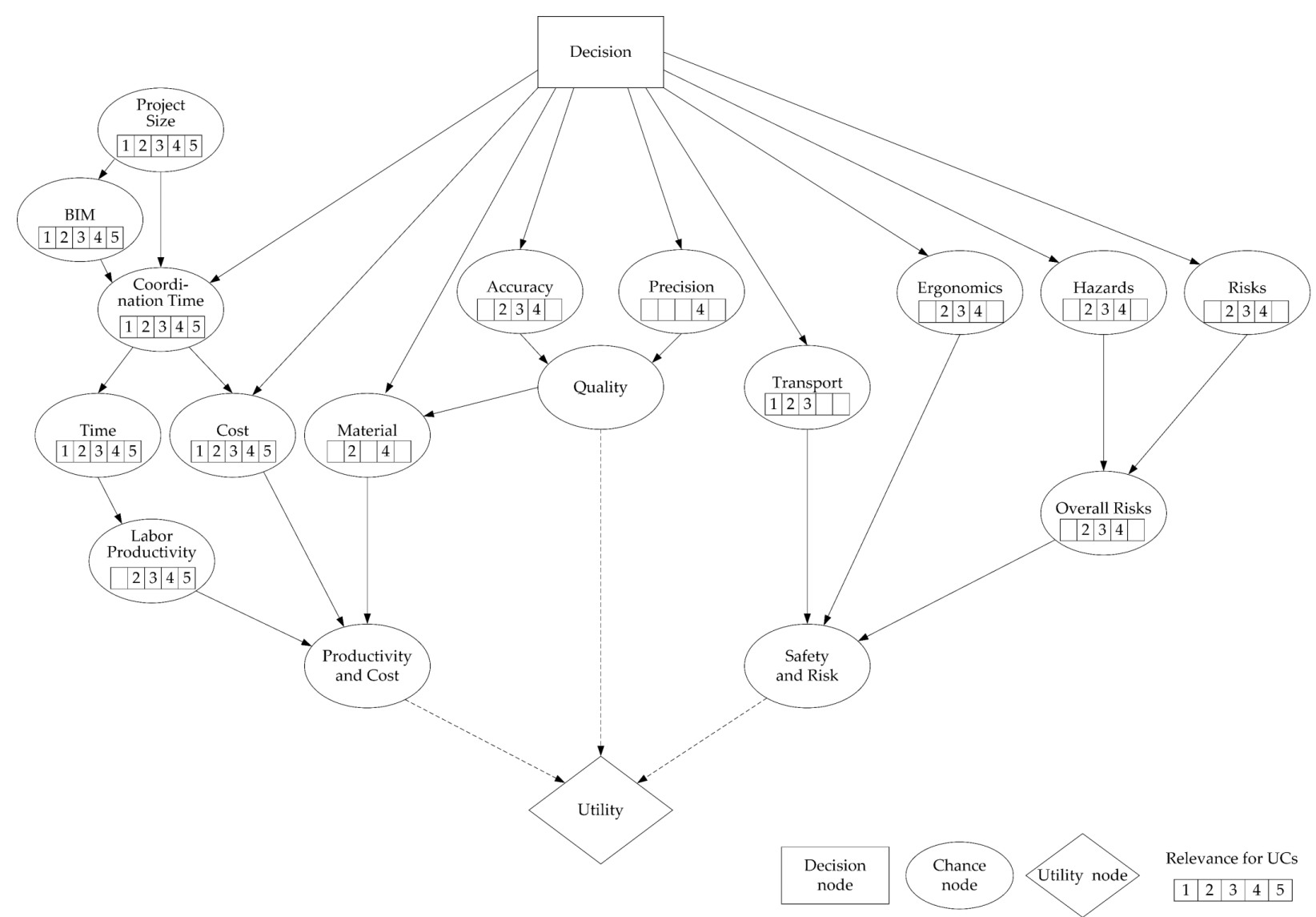

Figure 1. Decision model for UCs 1 to 5.

Table 2. List of variables to be considered in the evaluation.

\begin{tabular}{|c|c|c|c|c|c|c|c|c|c|}
\hline \multirow{2}{*}{ KPI } & \multirow{2}{*}{ Variable } & \multirow{2}{*}{ Relevance } & \multicolumn{5}{|c|}{ UC } & \multirow{2}{*}{$\begin{array}{l}\text { Supporting } \\
\text { Literature }\end{array}$} & \multirow{2}{*}{ Description } \\
\hline & & & 1 & 2 & 3 & 4 & 5 & & \\
\hline 1 & Time & \multirow{5}{*}{$\begin{array}{l}\text { Productivity } \\
\text { and Cost }\end{array}$} & $x$ & $x$ & $x$ & $x$ & $x$ & {$[12,29,34]$} & Process time needed to perform the task \\
\hline 2 & Cost & & $x$ & $x$ & $x$ & $x$ & $x$ & {$[12,26,28,34-37]$} & Average cost needed to perform the task \\
\hline 3 & Productivity & & & $\mathrm{x}$ & $x$ & $x$ & $x$ & {$[28,29,35,36]$} & Labour productivity \\
\hline 4 & Material & & & $\mathrm{x}$ & & $x$ & & {$[36,37]$} & $\begin{array}{c}\text { Consumption of material and resources } \\
\text { needed to perform the task }\end{array}$ \\
\hline- & $\begin{array}{l}\text { Coordination } \\
\text { time }\end{array}$ & & $\mathrm{x}$ & $\mathrm{x}$ & $x$ & $x$ & $x$ & {$[26]$} & $\begin{array}{c}\text { Time needed for preparing the execution of } \\
\text { the task }\end{array}$ \\
\hline 5 & Accuracy & \multirow{2}{*}{ Quality } & & \multirow[t]{2}{*}{$\mathrm{x}$} & \multirow[t]{2}{*}{$\mathrm{x}$} & $x$ & & \multirow{2}{*}[12,26,28,29,35,36]{} & Number of errors \\
\hline 6 & Precision & & & & & $x$ & & & Quality of the performed work \\
\hline 7 & Ergonomics & \multirow{5}{*}{$\begin{array}{l}\text { Safety and } \\
\text { Risk }\end{array}$} & \multirow{4}{*}{$x$} & $\mathrm{x}$ & $x$ & $x$ & & {$[12,26,37]$} & $\begin{array}{l}\text { Reduction in unfavourable body postures } \\
\text { during the execution of the task }\end{array}$ \\
\hline 8 & Transports & & & $x$ & $x$ & & & & $\begin{array}{c}\text { Number of transport processes of heavy } \\
\text { materials }\end{array}$ \\
\hline 9 & Hazards & & & $x$ & $x$ & $x$ & & [6] & $\begin{array}{c}\text { Time of exposure to hazards and use of } \\
\text { protection equipment }\end{array}$ \\
\hline 10 & Risks & & & $x$ & $x$ & $x$ & & {$[36,38]$} & $\begin{array}{l}\text { Reduction in the time of ladder use and } \\
\text { working at heights }\end{array}$ \\
\hline 11 & Overall risks & & $x$ & $x$ & $x$ & $x$ & & & $\begin{array}{c}\text { Overall assessment of risks that can lead to } \\
\text { accidents }\end{array}$ \\
\hline
\end{tabular}


Table 2. Cont.

\begin{tabular}{|c|c|c|c|c|c|c|c|c|c|}
\hline \multirow{2}{*}{ KPI } & \multirow{2}{*}{ Variable } & \multirow{2}{*}{ Relevance } & \multicolumn{5}{|c|}{ UC } & \multirow{2}{*}{$\begin{array}{c}\text { Supporting } \\
\text { Literature }\end{array}$} & \multirow{2}{*}{ Description } \\
\hline & & & 1 & 2 & 3 & 4 & 5 & & \\
\hline- & Project size & $\begin{array}{l}\text { Project } \\
\text { information }\end{array}$ & $\mathrm{x}$ & $x$ & $\mathrm{x}$ & $\mathrm{x}$ & $\mathrm{x}$ & {$[28,37]$} & $\begin{array}{l}\text { The project size can impact the decision of } \\
\text { whether adopting a robot or not }\end{array}$ \\
\hline- & BIM & & $x$ & $x$ & $\mathrm{x}$ & $x$ & $x$ & {$[12,26]$} & $\begin{array}{l}\text { The use of a BIM model is necessary for the } \\
\text { deployment of the collaborative robot that } \\
\text { is developed within the research project }\end{array}$ \\
\hline
\end{tabular}

For the sake of simplicity, and since the development process would be identical for all UCs, in the following we describe the development process of the prototype for UC4-marking and spraying. We define the decision model for UC4 in two steps. First, we eliminate the variables that are not directly involved in the decision. Then, we simplify the decision model for UC4 by combining variables. The resulting decision model for UC4 is presented in Figure 2. The final list of variables to be considered within the DSS, along with the states that they can assume, is presented in Table 3.

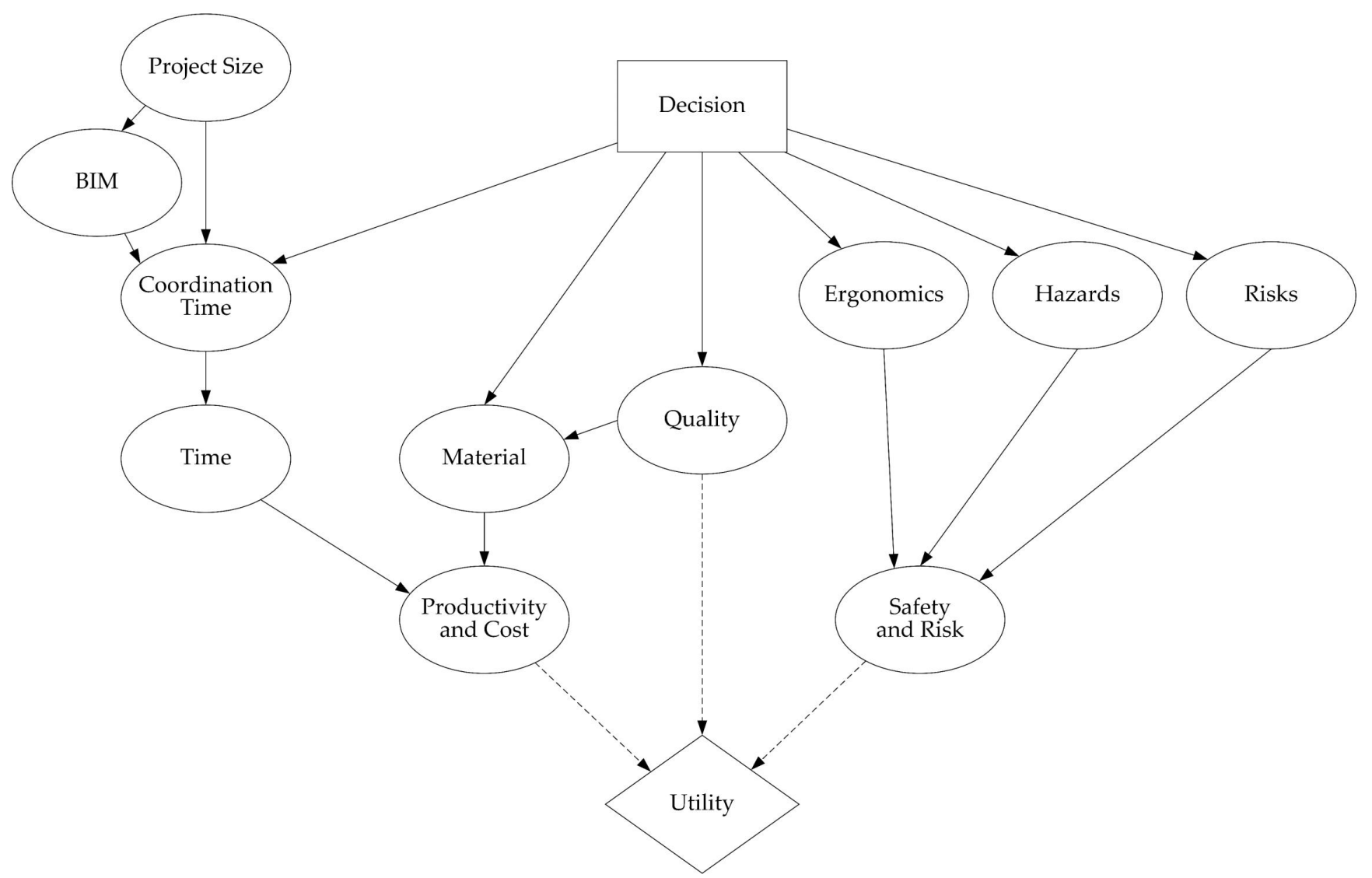

Figure 2. Simplified decision model for UC4-marking and spraying.

\subsubsection{Quantitative Part}

The elicitation of the quantitative part of the decision model involves the definition of the conditional probabilities, the utility function, and utilities in collaboration with the domain experts. We propose to elicit the conditional probability tables by mapping verbal statements of probability from "impossible" to "certain" to probabilities from 0 to $1[31,39,40]$. We defined the conditional probabilities for our use case scenario in collaboration with domain experts by performing educated guesses based on the expected performance of the collaborative robot in comparison to the conventional manual process. 
Each variable has been studied singularly to associate a mutually agreed verbal statement of probability. In Table 4 we present one of the conditional probability tables of our use case scenario as an example. In particular, we see the conditional probabilities $P(M \mid Q, D)$ of the variable material $(\mathrm{M})$, given quality $(\mathrm{Q})$, and decision $(\mathrm{D})$.

Table 3. Variables to be considered for UC4—marking and spraying.

\begin{tabular}{|c|c|c|c|}
\hline \multirow{2}{*}{$\begin{array}{l}\text { Variables } \\
\text { Decision }\end{array}$} & \multicolumn{3}{|c|}{ States of the Variables } \\
\hline & Collaborative robot & $\begin{array}{l}\text { Conventional } \\
\text { method }\end{array}$ & \\
\hline Ergonomics & $50 \%$ increase & unaltered & $50 \%$ reduction \\
\hline Hazards & $80 \%$ reduction & unaltered & $80 \%$ increase \\
\hline Risks & $50 \%$ reduction & unaltered & $50 \%$ increase \\
\hline Material & $10 \%$ reduction & unaltered & $10 \%$ increase \\
\hline BIM & available & not available & \\
\hline Coordination time & $20 \%$ increase & unaltered & $10 \%$ reduction \\
\hline Project size & $<10,000 \mathrm{~m}^{3}$ & $>10,000 \mathrm{~m}^{3}$ & \\
\hline Time & $20 \%$ reduction & unaltered & $20 \%$ increase \\
\hline Safety and Risk & $\begin{array}{l}30 \% \text { reduction in overall risk and } \\
\text { increase in safety }\end{array}$ & unaltered & $\begin{array}{l}30 \% \text { increase in overall risk } \\
\text { and reduction in safety }\end{array}$ \\
\hline Quality & $\begin{array}{l}20 \% \text { reduction in errors and } 30 \% \\
\text { reduction in variations }\end{array}$ & unaltered & $\begin{array}{l}20 \% \text { increase in errors and } \\
30 \% \text { increase in variations }\end{array}$ \\
\hline Productivity and Cost & $\begin{array}{l}20 \% \text { increase in productivity and } 10 \% \\
\text { reduction in cost }\end{array}$ & unaltered & $20 \%$ reduction \\
\hline
\end{tabular}

Table 4. Conditional probability table of coordination time $\mathrm{P}(\mathrm{M} \mid \mathrm{Q}, \mathrm{D})$.

\begin{tabular}{ccccc}
\hline \multirow{2}{*}{ Quality (Q) } & Decision (D) & \multicolumn{3}{c}{ Material (M) } \\
\cline { 3 - 5 } & & Reduced & Unaltered & Increased \\
\hline \multirow{2}{*}{ Increased } & Conventional method & 0.05 & 0.90 & 0.05 \\
& Collaborative robot & 0.90 & 0.05 & 0.05 \\
\hline \multirow{2}{*}{ Unaltered } & Conventional method & 0.10 & 0.80 & 0.10 \\
& Collaborative robot & 0.80 & 0.10 & 0.10 \\
\hline \multirow{2}{*}{ Reduced } & Conventional method & 0.00 & 0.50 & 0.50 \\
& Collaborative robot & 0.00 & 0.50 & 0.50 \\
\hline
\end{tabular}

Utility assessment or preference elicitation concerns the definition of the utility function, necessary for the construction of the decision-theoretic expert system [32]. We define a utility function that allows one to capture the preferences of the users for our use case. Our utility function is chosen as:

$$
\mathrm{U}=\mathrm{p} \times \mathrm{uP}+\mathrm{q} \times \mathrm{uQ}+\mathrm{s} \times \mathrm{uS}
$$

The parameters $\mathrm{p}, \mathrm{q}$, and s sum to one and represent the coefficients that allow the user to weight the utilities according to his preferences. $\mathrm{uP}, \mathrm{uQ}$, and $\mathrm{uS}$ represent the subjective utilities as defined in Table 5. Subjective utilities are assigned by ordering outcomes from worst to best [31]. We assigned utility 0 to the worst possible outcome, and utility 100 to the best possible outcome.

Table 5. Subjective utilities outcomes, where 0 is the worst outcome and 100 the best possible outcome.

\begin{tabular}{cccccc}
\hline Productivity & uP & Quality & uQ & Safety & uS \\
\hline Reduced & 0 & Reduced & 0 & Reduced & 0 \\
Unaltered & 100 & Unaltered & 100 & Unaltered & 100 \\
Increased & 100 & Increased & 100 & Increased & 100 \\
\hline
\end{tabular}




\subsection{Inference Engine}

We use the previously defined decision model for performing the computations. For this purpose, the model is defined and implemented by using the python wrapper pyAgrum for the $\mathrm{C}++$ aGrUM library for building and computing Bayesian networks [41] that allows one to perform computations based on the algorithms described in $[42,43]$. This implementation allows us to analyse the behaviour of the decision model and to verify if the model provides reasonable output.

\subsubsection{MEU Computation}

By applying the principle of MEU, we choose the decision that yields the highest expected utility [32]. The preferences are captured by the utility function $U(\mathrm{~s})$ (1) that assigns a number to the different states (Table 5). The expected utility $(E U)$ of a decision $(d)$, given evidence $(e)$ can be calculated by averaging the utility of the different outcomes with the probability $(P)$ that the outcome can be achieved [32]:

$$
\begin{gathered}
E U(d \mid \mathrm{e})=\sum_{s^{\prime}} P\left(\operatorname{Result}(d)=s^{\prime} \mid a, \mathrm{e}\right) \times U\left(s^{\prime}\right) \\
\text { decision }=\operatorname{argmax}_{d} E U(d \mid \mathrm{e})
\end{gathered}
$$

In Table 6 we see the results of the MEU computation when we consider different weightings of preferences $(p, q$, or $s)$. For equal weightings $(p=q=s)$ we see that the best rational decision is the collaborative robot $(\mathrm{R})$ with a MEU of 93.24 .

Table 6. Variation of results due to user interaction $(\mathrm{R}=$ collaborative robot, $\mathrm{C}=$ conventional

\begin{tabular}{|c|c|c|c|c|c|c|c|c|c|c|c|c|c|c|}
\hline \multirow{3}{*}{\multicolumn{3}{|c|}{ Preferences [\%] }} & \multicolumn{10}{|c|}{ Results with Evidence } & \multirow{3}{*}{\multicolumn{2}{|c|}{$V P I$}} \\
\hline & & & \multirow{2}{*}{\multicolumn{2}{|c|}{ Result }} & \multicolumn{4}{|c|}{ BIM } & \multicolumn{4}{|c|}{ Project Size } & & \\
\hline & & & & & \multicolumn{2}{|c|}{$\begin{array}{c}\text { Not } \\
\text { Available }\end{array}$} & \multicolumn{2}{|c|}{ Available } & \multicolumn{2}{|c|}{ Small } & \multicolumn{2}{|c|}{ Large } & & \\
\hline $\mathrm{p}$ & $q$ & $\mathrm{~s}$ & $\mathrm{D}$ & MEU & $\mathrm{D}$ & MEU & $\mathrm{D}$ & MEU & $\mathrm{D}$ & MEU & $\mathrm{D}$ & MEU & BIM & PS \\
\hline 33 & 33 & 33 & $\mathrm{R}$ & 93.24 & $\mathrm{C}$ & 95.56 & $\mathrm{R}$ & 95.28 & $\mathrm{C}$ & 95.71 & $\mathrm{R}$ & 95.18 & 4.72 & 4.74 \\
\hline 100 & 0 & 0 & $\mathrm{C}$ & 92.99 & $\mathrm{C}$ & 92.70 & $\mathrm{C}$ & 93.38 & $\mathrm{C}$ & 93.20 & $\mathrm{C}$ & 92.83 & 1.77 & 1.77 \\
\hline 80 & 10 & 10 & $\mathrm{C}$ & 93.79 & $\mathrm{C}$ & 93.57 & $\mathrm{C}$ & 94.10 & $\mathrm{C}$ & 93.95 & $\mathrm{C}$ & 93.66 & 1.92 & 1.92 \\
\hline 60 & 20 & 20 & $\mathrm{C}$ & 94.58 & $\mathrm{C}$ & 94.42 & $\mathrm{C}$ & 94.82 & $\mathrm{C}$ & 94.71 & $\mathrm{C}$ & 94.49 & 2.07 & 2.07 \\
\hline 50 & 25 & 25 & C & 94.98 & $\mathrm{C}$ & 94.85 & $\mathrm{R}$ & 94.15 & C & 95.09 & $\mathrm{R}$ & 94.03 & 2.09 & 2.12 \\
\hline 40 & 30 & 30 & C & 95.38 & C & 95.27 & $\mathrm{R}$ & 94.83 & C & 95.46 & $\mathrm{R}$ & 94.72 & 2.22 & 2.25 \\
\hline 0 & 100 & 0 & $\mathrm{R}$ & 94.34 & $\mathrm{R}$ & 94.99 & $\mathrm{R}$ & 95.15 & $\mathrm{R}$ & 93.57 & $\mathrm{R}$ & 95.08 & 5.65 & 5.65 \\
\hline 10 & 80 & 10 & $\mathrm{R}$ & 94.01 & $\mathrm{C}$ & 95.16 & $\mathrm{R}$ & 95.19 & $\mathrm{C}$ & 95.21 & $\mathrm{R}$ & 95.11 & 5.38 & 5.38 \\
\hline 20 & 60 & 20 & $\mathrm{R}$ & 93.68 & $\mathrm{C}$ & 95.33 & $\mathrm{R}$ & 95.23 & $\mathrm{C}$ & 95.42 & $\mathrm{R}$ & 95.14 & 5.10 & 5.11 \\
\hline 25 & 50 & 25 & $\mathrm{R}$ & 93.51 & C & 95.41 & $\mathrm{R}$ & 95.24 & C & 95.53 & $\mathrm{R}$ & 95.16 & 4.96 & 4.98 \\
\hline 30 & 40 & 30 & $\mathrm{R}$ & 93.35 & $\mathrm{C}$ & 95.50 & $\mathrm{R}$ & 95.26 & C & 95.64 & $\mathrm{R}$ & 95.17 & 4.81 & 4.84 \\
\hline 0 & 0 & 100 & $\mathrm{R}$ & 99.91 & $\mathrm{R}$ & 99.91 & $\mathrm{R}$ & 99.91 & $\mathrm{R}$ & 99.91 & $\mathrm{R}$ & 99.91 & 0.00 & 0.00 \\
\hline 10 & 10 & 80 & $\mathrm{R}$ & 97.91 & $\mathrm{R}$ & 97.19 & $\mathrm{R}$ & 98.52 & $\mathrm{R}$ & 97.23 & $\mathrm{R}$ & 98.49 & 1.06 & 1.06 \\
\hline 20 & 20 & 60 & $\mathrm{R}$ & 95.90 & $\mathrm{R}$ & 94.48 & $\mathrm{R}$ & 97.13 & $\mathrm{R}$ & 94.56 & $\mathrm{R}$ & 97.07 & 2.14 & 2.14 \\
\hline 25 & 25 & 50 & $\mathrm{R}$ & 94.90 & $\mathrm{R}$ & 93.13 & $\mathrm{R}$ & 96.43 & $\mathrm{R}$ & 93.22 & $\mathrm{R}$ & 96.36 & 2.68 & 2.68 \\
\hline 30 & 30 & 40 & $\mathrm{R}$ & 93.90 & C & 95.90 & $\mathrm{R}$ & 95.74 & $\mathrm{C}$ & 96.04 & $\mathrm{R}$ & 95.65 & 4.22 & 4.24 \\
\hline
\end{tabular}
method).

\subsubsection{VOI Analysis}

VOI analysis allows one to define which information-gathering activities should be performed by the user. In our case, we calculate the Value of Perfect Information (VPI), also called value of clairvoyance, on the variables that are uncertain [33]. If exact evidence of variables can be obtained, VPI can be calculated as follows [32]:

$$
V P I_{e}\left(E_{j}\right)=\left(\sum_{k} P\left(E_{j}=e_{j k} \mid \mathrm{e}\right) \times E U\left(\delta_{j k} \mid \mathrm{e}, E_{j}=e_{j k}\right)\right)-E U(\delta \mid \mathrm{e})
$$


where $E U(\delta \mid \mathbf{e})$ is the Expected Utility $(E U)$ of the current best decision $\delta, E U\left(\delta_{j k} \mid \mathbf{e}, E_{j}=e_{j k}\right)$ is the $E U$ of the new best decision $\delta$ with evidence $E_{j}$ that is averaged over all the possible values $e_{j k}$ that we may have for $E_{j}$. As VPI can be only computed for variables that are non-descendants of decision nodes [43], we can perform this computation for the variables BIM and Project size (PS). The EU of the new best action with evidence can be obtained by adding an influence arc from the uncertain variables BIM and PS to the decision node [33]. In Table 6, we see the result of the VOI computations when we consider different weightings of preferences ( $\mathrm{p}, \mathrm{q}$, or $\mathrm{s})$. For equal weightings $(\mathrm{p}=\mathrm{q}=\mathrm{s})$, we see that $\operatorname{VPI}(\mathrm{PS})>\operatorname{VPI}(\mathrm{BIM})$. This means that the best information to be acquired is the value of Project Size (PS).

\subsection{User Interaction}

The user can interact with the system by stating his preferences, by inserting evidence, and by answering to the questions of the inference engine to get advice on the best rational decision [27]. The user has the option to influence the advice through a targeted interaction with the system. The influence of the user interactions on the system, as well as the information that should be provided by the user, are shown in Table 6 . We see how different preference statements ( $p, q$, or s) lead to a different advice (D) of the system, how the advice changes if we add evidence on the chance nodes BIM and PS, and which would be the best information to be acquired by the user.

\subsection{Evaluation}

To evaluate whether the system provides reasonable output, the obtained results are analysed in collaboration with the domain experts that contributed to the development of the DSS following an axiomatic design guideline. For the development of the knowledgebase, we agreed on the qualitative and quantitative part of the decision model also involving the domain experts. The qualitative part concerns both the definition of the variables to be considered within the DSS and their relevance for the different use cases, as well as the structure of the complete decision model, and the simplified decision model for UC4-marking and spraying. The quantitative part concerns the definition of the numbers to be used for performing the computations within the inference engine. Here, we agreed with the domain experts on the utility function, preferences, and on the subjective utilities that are selected so that none of the available options can penalised or preferred by the system. Due to missing comparison values between robot and conventional method, we defined the conditional probability tables by performing educated guesses, by combining both experience and the expected performance of the system.

The behaviour due to user interaction is also analysed in collaboration with domain experts. For this reason, we explained how the inference engine is constructed and how the system is reasoning and reacting to user interventions. The changes in the system's advice due to the user's intervention are shown in Table 6:

- if we consider equal weightings of preferences without adding evidence the preferred solution is the collaborative robot. Results change if we set evidence on the chance nodes BIM and PS. The conventional system is suggested if the BIM model is not available or if we have a small project. The robotic system is suggested if a BIM model is available or if we have a large project. Looking at the VPI we see that the best information to be acquired is the project size.

- if we focus on productivity and cost, the preferred solution is mostly the conventional system. Additionally, different settings of preferences and evidence have an impact on the decision and on the best information to be acquired by the user.

- if we focus on quality, the preferred solution is mostly the collaborative robot. The conventional system is mostly preferred if the BIM model is not available or if we have a small project.

- if we focus on safety, the preferred solution is mostly the collaborative robot. Here, the conventional manual process is suggested for only one preference setting and when the BIM model is not available or if we have a small project. 
The evaluation of the output with domain experts has been considered satisfactory.

\section{Discussion}

Previous studies have shown that impact of the introduction of robotic systems on the construction site requires a careful evaluation of their potential benefits and shortcomings on the construction process, which is very challenging due to the lack of available performance data of construction robots $[12,26]$. The lack of available data concerns both the conventional processes, where we have a lack of standardised work processes that cause uncertainty [14], and the processes that employ new technologies, which have not yet been sufficiently tested in real world scenarios [26].

Within this work, this challenge is addressed by developing a decision-theoreticexpert system that can perform rational reasoning and allows one to fill the lack of data with expert knowledge. The application of the guideline for the design of DSS [27], with a fixed development procedure, simplified the development process and made it possible to involve domain experts easily in the process. The close collaboration with the domain experts makes the underlying reasoning processes of the system more transparent and, therefore, increases the acceptance of the DSS. The increasing adoption of BIM in construction with the provision of digital models that contain both geometric and semantic data can be considered as a necessary condition for the efficient deployment of construction robots.

\section{Conclusions}

This work provides two contributions for decision support in the field of robotic equipment adoption in construction processes. On the one hand, it shows the applicability of an axiomatic design guideline for the collaborative design of DSS for robotic equipment adoption in construction processes, and it can serve as a basis for defining a software-tool that allows the systematic development of DSS. On the other hand, it confirms the ability of decision-theoretic expert systems to represent construction related decision problems in an adequate way. The adopted approach allows us to highlight both shortcomings and advantages of the robotic systems to be developed within the research project and conventional construction methods, by systematically evaluating their impacts on productivity and cost, quality, and safety and risk. The involvement of domain experts allows us to define a DSS that acts reasonably and to fill the gaps in the availability of data often found in decision problems that are related to construction execution processes.

The applicability of the approach is demonstrated by means of an exemplary UC of an ongoing EU-funded project. The conditional probabilities needed for the computations were defined by making educated guesses based on the target performance that the collaborative robot should reach in comparison to the conventional manual process. The values will be refined when tangible results of the testing activities will be available. Further, the DSS will be extended to all UCs of the project and allow the user to choose the different tasks that can be performed by the system.

Author Contributions: Conceptualization, C.M. and A.G.; methodology, C.M. and A.G.; investigation, C.M.; writing - original draft preparation, C.M. and A.G.; supervision, D.T.M. All authors have read and agreed to the published version of the manuscript.

Funding: This research has received funding from the European Union's Horizon 2020 research and innovation program under grant agreement No 101016007. (Project CONCERT—CONfigurable CollaborativE Robot Technologies).

Acknowledgments: The authors would like to thank the group guided by Lech Własak at Budimex, Poland, project partner in CONCERT, for collaborating in the development and evaluation of the prototype. Special thanks are also directed to Cinzia Slongo from Fraunhofer Italia for her support during the development and evaluation of the prototype. 
Conflicts of Interest: The authors declare no conflict of interest. The funders had no role in the design of the study; in the collection, analyses, or interpretation of data; in the writing of the manuscript; or in the decision to publish the results.

\section{References}

1. Dirican, C. The Impacts of Robotics, Artificial Intelligence On Business and Economics. Procedia-Soc. Behav. Sci. 2015, 195, 564-573. [CrossRef]

2. Davila Delgado, J.M.; Oyedele, L.; Ajayi, A.; Akanbi, L.; Akinade, O.; Bilal, M.; Owolabi, H. Robotics and automated systems in construction: Understanding industry-specific challenges for adoption. J. Build. Eng. 2019, 26, 100868. [CrossRef]

3. Pasetti Monizza, G.; Bendetti, C.; Matt, D.T. Parametric and Generative Design techniques in mass-production environments as effective enablers of Industry 4.0 approaches in the Building Industry. Autom. Constr. 2018, 92, 270-285. [CrossRef]

4. Vähä, P.; Heikkilä, T.; Kilpeläinen, P.; Järviluoma, M.; Gambao, E. Extending automation of building construction-Survey on potential sensor technologies and robotic applications. Autom. Constr. 2013, 36, 168-178. [CrossRef]

5. Carra, G.; Argiolas, A.; Bellissima, A.; Niccolini, M.; Ragaglia, M. Robotics in the Construction Industry: State of the Art and Future Opportunities. In Proceedings of the 35th International Symposium on Automation and Robotics in Construction (ISARC), Berlin, Germany, 20-25 July 2018; pp. 866-873.

6. Aghimien, D.O.; Aigbavboa, C.O.; Oke, A.E.; Thwala, W.D. Mapping out research focus for robotics and automation research in construction-related studies: A bibliometric approach. J. Eng. Des. Technol. 2019, 18, 1063-1079. [CrossRef]

7. Son, H.; Kim, C.; Kim, H.; Han, S.H.; Kim, M.K. Trend analysis of research and development on automation and robotics technology in the construction industry. KSCE J. Civ. Eng. 2010, 14, 131-139. [CrossRef]

8. Bogue, R. What are the prospects for robots in the construction industry? Ind. Robot. Int. J. 2018, 45, 1-6. [CrossRef]

9. Deloitte Global Powers of Construction. 2018. Available online: https://www2.deloitte.com/gr/en/pages/energy-andresources/articles/deloitte-global-powers-of-construction-2018.html (accessed on 10 July 2021).

10. Hampson, K.D.; Kraatz, J.A.; Sanchez, A.X. The Global Construction Industry and R\&D. In RED Investment and Impact in the Global Construction Industry; Routledge: New York, NY, USA, 2014; pp. 4-23.

11. Arayici, Y.; Coates, P. A system engineering perspective to knowledge transfer: A case study approach of BIM adoption. Virtual Real.-Hum. Comput. Interact. 2012, 2006, 179-206.

12. Brosque, C.; Skeie, G.; Fischer, M. Comparative Analysis of Manual and Robotic Concrete Drilling for Installation Hangers. J. Constr. Eng. Manag. 2021, 147. [CrossRef]

13. Marcher, C.; Giusti, A.; Schimanski, C.P.; Matt, D.T. Application of Decision Support Systems for Advanced Equipment Selection in Construction. In Cooperative Design, Visualization, and Engineering; Luo, Y., Ed.; Lecture Notes in Computer Science; Springer International Publishing: Cham, Switzerland, 2019; Volume 11792, pp. 229-235. ISBN 978-3-030-30948-0.

14. Dubois, A.; Gadde, L.-E. The construction industry as a loosely coupled system: Implications for productivity and innovation. Constr. Manag. Econ. 2002, 20, 621-631. [CrossRef]

15. Hastak, M. Advanced automation or conventional construction process? Autom. Constr. 1998, 7, 299-314. [CrossRef]

16. Marcher, C.; Giusti, A.; Matt, D.T. Decision Support in Building Construction: A Systematic Review of Methods and Application Areas. Buildings 2020, 10, 170. [CrossRef]

17. Marzouk, M.; Abubakr, A. Decision support for tower crane selection with building information models and genetic algorithms. Autom. Constr. 2016, 61, 1-15. [CrossRef]

18. Alshibani, A.; Elassir, H.; Al-Najjar, M.; Hamida, H. AHP based approach for crane selection of building construction in Saudi Arabia: A case study. In Proceedings of the Annual Conference-Canadian Society for Civil Engineering, Montreal, QC, Canada, 12-15 June 2019.

19. Temiz, I.; Calis, G. Selection of Construction Equipment by using Multi-criteria Decision Making Methods. In Procedia Engineering; Elsevier Ltd.: Amsterdam, The Netherlands, 2017; Volume 196, pp. 286-293.

20. Jankovic, I.; Djenadic, S.; Ignjatovic, D.; Jovancic, P.; Subaranovic, T.; Ristovic, I. Multi-criteria approach for selecting optimal dozer type in open-cast coal mining. Energies 2019, 12, 2245. [CrossRef]

21. Zeynalian, M.; Dehaghi, I.K. Choice of optimum combination of construction machinery using modified advanced programmatic risk analysis and management model. Sci. Iran. 2018, 25, 1015-1024. [CrossRef]

22. Kouch, A.M.; Illikainen, K.; Perälä, S. Key Factors of an Initial BIM Implementation Framework for Small and Medium-sized Enterprises (SMEs); International Association for Automation and Robotics in Construction (IAARC): Taipei, Taiwan, 2018; pp. 904-912.

23. Azhar, S. Building Information Modeling (BIM): Trends, Benefits, Risks, and Challenges for the AEC Industry. Leadersh. Manag. Eng. 2011, 11, 241-252. [CrossRef]

24. Follini, C.; Magnago, V.; Freitag, K.; Terzer, M.; Marcher, C.; Riedl, M.; Giusti, A.; Matt, D.T. Bim-integrated collaborative robotics for application in building construction and maintenance. Robotics 2021, 10, 2. [CrossRef]

25. Giusti, A.; Magnago, V.; Siegele, D.; Terzer, M.; Follini, C.; Garbin, S.; Marcher, C.; Steiner, D.; Schweigkofler, A.; Riedl, M. BALTO: A BIM-Integrated Mobile Robot Manipulator for Precise and Autonomous Disinfection in Buildings against COVID-19. In Proceedings of the 2021 IEEE 17th International Conference on Automation Science and Engineering (CASE), Lyon, France, 23-27 August 2021; pp. 1730-1737. 
26. Brosque, C.; Skeie, G.; Örn, J.; Jacobson, J.; Lau, T.; Fischer, M. Comparison of construction robots and traditional methods for drilling, drywall, and layout tasks. In Proceedings of the 2020 International Congress on Human-Computer Interaction, Optimization and Robotic Applications (HORA), Ankara, Turkey, 26-28 June 2020; pp. 1-14.

27. Marcher, C.; Rauch, E.; Giusti, A.; Matt, D.T. Decision Support Systems in Building Construction-An Axiomatic Design Approach. In Proceedings of the IOP Conference Series: Materials Science and Engineering, The 14th International Conference on Axiomatic Design (ICAD 2021), Lisbon, Portugal, 23-25 June 2021; Volume 1174, p. 012004.

28. Makovetskaya, E.; Deniskina, A.; Krylov, E.; Urumova, F. Organizational optimization of construction processes by virtue of robotization. In E3S Web of Conferences; Zheltenkov, A., Ed.; EDP Sciences: Les Ulis, France, 2019; Volume 91, p. 02036.

29. Yan, R.-J.; Kayacan, E.; Chen, I.-M.; Tiong, L.K.; Wu, J. QuicaBot: Quality Inspection and Assessment Robot. IEEE Trans. Autom. Sci. Eng. 2019, 16, 506-517. [CrossRef]

30. Suh, N.P. Axiomatic Design Theory for Systems. Res. Eng. Des. 1998, 10, 189-209. [CrossRef]

31. Kjærulff, U.B.; Madsen, A.L. Bayesian Networks and Influence Diagrams: A Guide to Construction and Analysis, 2nd ed.; Information Science and Statistics; Springer: New York, NY, SUA, 2013; ISBN 978-1-4614-5103-7.

32. Russell, S.J.; Norvig, P.; Davis, E. Artificial Intelligence: A Modern Approach, 3rd ed.; Prentice Hall Series in Artificial Intelligence; Prentice Hall: Upper Saddle River, NJ, USA, 2010; ISBN 978-0-13-604259-4.

33. Howard, R.A.; Matheson, J.E. Influence Diagrams. Decis. Anal. 2005, 2, 127-143. [CrossRef]

34. Liang, C.-J.; Kang, S.-C.; Lee, M.-H. RAS: A robotic assembly system for steel structure erection and assembly. Int. J. Intell. Rob. Appl. 2017, 1, 459-476. [CrossRef]

35. Taghavi, M.; Iturralde, K.; Bock, T. Cable-driven parallel robot for curtain wall modules automatic installation. In Proceedings of the 35th International Symposium on Automation and Robotics in Construction (ISARC), Berlin, Germany, 20-25 July 2018; pp. 396-403.

36. Hu, R.; Iturralde, K.; Linner, T.; Zhao, C.; Pan, W.; Pracucci, A.; Bock, T. A simple framework for the cost-benefit analysis of single-task construction robots based on a case study of a cable-driven facade installation robot. Buildings 2021, 11, 8. [CrossRef]

37. Dakhli, Z.; Lafhaj, Z. Robotic mechanical design for brick-laying automation. Cogent Eng. 2017, 4, 1361600. [CrossRef]

38. Lee, S.; Yu, S.; Choi, J.; Han, C. A methodology to quantitatively evaluate the safety of a glazing robot. Appl. Ergon. 2011, 42, 445-454. [CrossRef]

39. Renooij, S.; Witteman, C. Talking probabilities: Communicating probabilistic information with words and numbers. Int. J. Approx. Reason. 1999, 22, 169-194. [CrossRef]

40. van der Gaag, L.C.; Renooij, S.; Witteman, C.L.M.; Aleman, B.M.P.; Taal, B.G. Probabilities for a probabilistic network: A case study in oesophageal cancer. Artif. Intell. Med. 2002, 25, 123-148. [CrossRef]

41. Gonzales, C.; Torti, L.; Wuillemin, P.-H. aGrUM: A Graphical Universal Model Framework. In Advances in Artificial Intelligence: From Theory to Practice; Benferhat, S., Tabia, K., Ali, M., Eds.; Springer International Publishing: Cham, Switzerland, 2017; Volume 10351, pp. 171-177. ISBN 978-3-319-60044-4.

42. Liu, Q.; Ihler, A.T. Belief propagation for structured decision making. arXiv 2012, arXiv:1210.4897v1.

43. Nilsson, D.; Lauritzen, S.L. Evaluating influence diagrams using LIMIDs. arXiv 2013, arXiv:1301.3881v1. 